OPEN ACCESS

Edited by:

Jixin Zhong,

Case Western Reserve University,

United States

Reviewed by:

Ding Xinchun,

Indiana University - Purdue

University Indianapolis,

United States

Shanzhong Gong,

University of Texas at Austin,

United States

*Correspondence: Danièle Noël

daniele.noe/@inserm.fr

tThese authors have contributed equally to this work.

Specialty section: This article was submitted to Inflammation,

a section of the journal

Frontiers in Immunology

Received: 22 June 2017 Accepted: 02 August 2017 Published: 01 September 2017

Citation:

Fonteneau G, Bony C,

Goulabchand R, Maria ATJ, Le Quellec A, Rivière S, Jorgensen C,

Guilpain P and Noël D (2017) Serum-Mediated Oxidative Stress from Systemic Sclerosis Patients Affects Mesenchymal Stem Cell Function.

Front. Immunol. 8:988. doi: 10.3389/fimmu.2017.00988

\section{Serum-Mediated Oxidative Stress from Systemic Sclerosis Patients Affects Mesenchymal Stem Cell Function}

\author{
Guillaume Fonteneau ${ }^{1}$, Claire Bony ${ }^{1}$, Radjiv Goulabchand ${ }^{1,2}$, Alexandre T. J. Maria ${ }^{1,2}$, \\ Alain Le Quellec ${ }^{1,2}$, Sophie Rivière ${ }^{1,2}$, Christian Jorgensen ${ }^{1,3}$, Philippe Guilpain ${ }^{1,2+}$ \\ and Danièle Noël ${ }^{1,3 * t}$

\begin{abstract}
${ }^{1}$ IRMB, INSERM, Montpellier University, Montpellier, France, ${ }^{2}$ Department of Internal Medicine, Multiorganic Diseases, Saint-Eloi Hospital, Montpellier, France, ${ }^{3}$ Clinical Immunology and Osteoarticular Diseases Therapeutic Unit, Lapeyronie Hospital, Montpellier, France
\end{abstract}

Objectives: Properties of mesenchymal stromal/stem cells (MSCs) from systemic sclerosis (SSc) patients have been reported to be altered. MSC-based therapy may therefore rely on the use of allogeneic MSCs from healthy subjects. Here, we investigated whether heterologous MSCs could exhibit altered properties following exposure to oxidative environment of SSc sera.

Methods: Human bone marrow-derived MSCs were cultured in the presence of various sera: control human serum $A B(S A B), S A B$ with $\mathrm{HOCl}$-induced AOPPs at 400 or $1,000 \mu \mathrm{mol} / \mathrm{L}\left(\mathrm{SAB}_{400}\right.$ or $\mathrm{SAB}_{1000}$, respectively), or $\mathrm{H}_{2} \mathrm{O}_{2}$-induced AOPPs or SSc patient serum (PS). Proliferation, apoptosis, and senescence rates of MSCs were evaluated after 3, 6, and 10 days in culture. Reactive oxygen species and nitric oxide production were quantified at $24 \mathrm{~h}$. Trilineage potential of differentiation was tested after 21 days in specific culture conditions and immunosuppressive function measured in a T lymphocyte proliferative assay.

Results: In the presence of oxidative environment of PS, MSCs retained their proliferative potential and survived for at least the first 3 days of exposure, while the number of senescent MSCs increased at day 6 and apoptosis rate at day 10. Exposure to PS enhanced the antioxidant capacity of MSCs, notably the expression of SOD2 antioxidant gene. By contrast, the osteoblastic/adipogenic potential of MSCs was increased, whereas their immunosuppressive function was slightly reduced.

Discussion: Although some functional properties of MSCs were affected upon culture with PS, evidence from preclinical studies and the present one suggested that MSCs can adapt to the oxidative environment and exert their therapeutic effect.

Keywords: mesenchymal stem cells, systemic sclerosis, cell therapy, oxidative stress, advanced oxidation protein product

Abbreviations: AOPP, advanced oxidation protein product; $\mathrm{HOCl}$, hypochloric acid; $\mathrm{H} 2 \mathrm{O} 2$, hydrogen peroxide; $\mathrm{MSC}$, mesenchymal stromal/stem cell; PBMC, peripheral blood mononuclear cell; PS, patient serum; RNS, reactive nitric species; ROS, reactive oxygen species; $\mathrm{NO}$, nitric oxide; $\mathrm{SAB}$, serum $\mathrm{AB}$; $\mathrm{SSc}$, systemic sclerosis. 


\section{INTRODUCTION}

Systemic sclerosis (SSc) (also called scleroderma) is a rare autoimmune disorder characterized by multiorgan fibrosis, vascular involvement, and production of autoantibodies. SSc exhibits a severe prognosis associated with specific organ involvements and premature mortality and can still be considered as an intractable disease. Oxidative stress plays a crucial role in the development of SSc, leading to fibroblast proliferation and endothelial cell apoptosis. This role is illustrated by the link between environmental exposure to oxidants and professional disease (1) and also by the increased levels of oxidative markers [such as advanced oxidation protein products (AOPP)] observed in serum of SSc patients (2). Serum of SSc patients with diffuse cutaneous forms contained AOPP concentrations of $400 \mu \mathrm{mol} / \mathrm{L}$ of chloramine-T equivalents, while those levels are around $200 \mu \mathrm{mol} / \mathrm{L}$ of chloramine-T equivalents in limited cutaneous forms of SSc and healthy individuals (3). AOPPs are the results of protein oxidation by either hypochlorous acid $(\mathrm{HOCl})$ or hydrogen peroxide $\left(\mathrm{H}_{2} \mathrm{O}_{2}\right)$ and appear to contribute to disease pathophysiology. In addition, SSc serum can induce the production of different types of reactive nitric species (RNS) and reactive oxygen species (ROS), selectively activating endothelial cells or fibroblasts (2). Thus, SSc serum represents an oxidative environment specific to the disease that can also trigger amplification loop leading to vasculopathy and fibrosis.

Because of their trophic and immunomodulatory properties, mesenchymal stromal/stem cells (MSCs) represent one of the most promising therapeutic approaches in SSc. MSCs are non-hematopoietic multipotent progenitor cells, which can be isolated from bone marrow, adipose tissue, or umbilical cord, and exhibit a tripotential of differentiation toward adipocytes, chondrocytes, and osteoblasts (4). They have proven efficacy in several animal models of fibrosis and in the murine model of $\mathrm{HOCl}$-induced SSc (5). In addition, the therapeutic interest of allogeneic MSCs is being evaluated in SSc patients in phase I/II studies (NCT00962923 and NCT02213705).

Noteworthy, allogeneic MSC-based therapy could appear safer than autologous approach in SSc. Indeed, SSc-MSCs were shown to display altered phenotypical and functional properties. They expressed higher levels of transforming growth factor (TGF)-BRII (6), $\alpha$-smooth muscle actin, SM22 $\alpha$ genes (7), and senescence markers (8) as well as enhanced pro-angiogenic activity (9). Since resident MSCs obtained from SSc patients (SSc-MSCs) may present altered functions, use of allogeneic MSCs could be more appropriate in the clinics and has already shown some promising results (10). Yet, the possibility that heterologous MSCs could exhibit altered properties following exposure to SSc oxidative environment has not been investigated. Here, we evaluated whether oxidative stress, and particularly $\mathrm{HOCl}$ and induced AOPPs, might affect the characteristics and functional properties of heterologous human MSCs when exposed to serum from SSc patients.

\section{MATERIALS AND METHODS}

\section{Human Sample Collection}

Seventeen patients were included for serum collection. Their clinical and biological characteristics are indicated in Table $\mathbf{1}$.
Human bone marrow-derived MSCs were isolated from patients undergoing hip replacement surgery as described earlier (11). Both human samples were obtained from patients with written informed consent from all subjects in accordance with the Declaration of Helsinki. This study was carried out in accordance with the recommendations of Committee for Person Protection of Languedoc-Roussillon and approved by the French Ministry of Higher Education and Research (DC-2010-1185 for MSC and DC-2014-2328 for SSc serum). MSCs were characterized by phenotyping and trilineage differentiation potential as described in Ref. (12) and used before passage 5. They were maintained in proliferative medium consisting in $\alpha$-MEM (Lonza), $1 \mathrm{ng} / \mathrm{mL}$ of basic fibroblast growth factor (R\&D Systems), $100 \mu \mathrm{g} / \mathrm{mL}$ penicillin/streptomycin (Lonza), $2 \mathrm{mM}$ glutamine (Lonza), and supplemented with $10 \%$ fetal calf serum (FCS) before use in experimental settings. Blood from SSc patients was centrifuged at 2,000 $\mathrm{g}$ for $15 \mathrm{~min}$, and patient serum (PS) stored at $-80^{\circ} \mathrm{C}$. Serum AB (SAB) was a pool of 200 human male AB plasma purchased from Sigma-Aldrich (ref H4522). Human blood was purchased from the Etablissement Français du Sang (Toulouse). Human peripheral blood mononuclear cells (PBMCs) were isolated by Ficoll (GE Healthcare) according to standard procedures.

\section{Oxidative Medium Preparation}

Healthy SAB $(15 \mathrm{~mL})$ was oxidized with $15 \mathrm{~mL}$ hypochlorite $(\mathrm{HOCl})$ at room temperature for $1 \mathrm{~h}$. $\mathrm{HOCl}$ was produced by adding $166 \mu \mathrm{L}$ of $\mathrm{NaClO}$ solution to $11.1 \mathrm{~mL}$ of $\mathrm{KH}_{2} \mathrm{PO}_{4}$ solution (100 mM, pH 7.2), and $\mathrm{HOCl}$ concentration was determined by spectrophotometry at $292 \mathrm{~nm}$ as described earlier (2). Oxidized serum was then dialyzed in $\mathrm{PBS}$ at $4^{\circ} \mathrm{C}$ overnight using a semipermeable membrane (3.5 K molecular weight cut-off; Slide-A-Lyzer dialysis cassette, ThermoFisher Scientific). The AOPP level in oxidized SAB and PS was determined by spectrophotometry as previously described (2) and expressed as chloramine-T equivalents $(\mu \mathrm{mol} / \mathrm{L})$. Oxidized $\mathrm{SAB}$ was diluted with $\mathrm{SAB}$ to obtain a defined AOPP level of $400 \mu \mathrm{mol} / \mathrm{L}\left(\mathrm{SAB}_{400}\right)$ or $1,000 \mu \mathrm{mol} / \mathrm{L}$ $\left(\mathrm{SAB}_{1000}\right)$. As control, $\mathrm{H}_{2} \mathrm{O}_{2}$ was added in culture medium with $\mathrm{SAB}\left(\mathrm{SAB}_{\mathrm{H}_{22} 2}\right)$ at $150 \mu \mathrm{M}$ final concentration, which corresponded to $680 \mu \mathrm{mol} / \mathrm{L}$ of AOPPs.

\section{Proliferation Assay}

MSCs were plated at 10,000 cells $/ \mathrm{cm}^{2}$ in six-wells plates in proliferative medium supplemented with $5 \%$ human serum (SAB, $\mathrm{SAB}_{400}, \mathrm{SAB}_{1000}, \mathrm{SAB}_{\mathrm{H} 2 \mathrm{O} 2}$, or PS). Media were changed every 3 days, and viable cells were counted using a Malassez hemocytometer at 3,6 , and 10 days. Results were expressed as the percentage of proliferation \pm SEM and normalized at $100 \%$ for initially plated cell number.

\section{Apoptosis Assay}

MSCs were plated at 10,000 cells $/ \mathrm{cm}^{2}$ in six-well plates in proliferative medium containing $5 \%$ human serum $\left(\mathrm{SAB}, \mathrm{SAB}_{400}\right.$, $\mathrm{SAB}_{1000}, \mathrm{SAB}_{\mathrm{H} 2 \mathrm{O} 2}$, or PS). Number of apoptotic cells was evaluated by Annexin V and 7-AAD labeling. Briefly, $10^{5}$ MSCs were suspended in $300 \mu \mathrm{L}$ Annexin V binding buffer (BD Biosciences) and incubated with $2.5 \mu \mathrm{L}$ of fluorescein isothiocyanate-conjugated 
TABLE 1 | Clinical characteristics of SSc patients.

\begin{tabular}{|c|c|c|c|c|c|c|c|c|}
\hline $\begin{array}{l}\text { Patient } \\
\text { (N) }\end{array}$ & $\begin{array}{c}\text { Age at } \\
\text { diagnosis } \\
\text { (years)/sex }\end{array}$ & $\begin{array}{c}\text { Disease } \\
\text { duration from } \\
\text { diagnosis } \\
\text { (years) }\end{array}$ & Type of SSc & Autoantibodies & Clinical involvement & $\begin{array}{l}\text { Immunosuppressive } \\
\text { drugs at } \\
\text { sampling time }\end{array}$ & Other treatments & $\begin{array}{l}\text { AOPP plasma level } \\
\text { (chloramine-T } \\
\text { equivalents, } \\
\mu \mathrm{mol} / L \text { ) }\end{array}$ \\
\hline 1 & $54 / F$ & 16 & d-SSc & Scl70 & CIPO, DU, GER, ILD, PAH & $\begin{array}{l}\text { Low-dose steroids, } \\
\text { azathioprine }\end{array}$ & $\begin{array}{l}\text { Bosentana, tadalafila, low-dose } \\
\text { steroids, cyclophosphamide, MMF, } \\
\text { sildenafil, treprostinil, tadalafil, iloprost }\end{array}$ & 121 \\
\hline 2 & $27 / F$ & 16 & d-SSc & Scl70, ANA & DU, GER, ILD & None & Bosentana, sildenafil $^{a}$ & 253 \\
\hline 3 & $61 / F$ & 2 & Ic-SSc & $\mathrm{Cm}, \mathrm{PM} / \mathrm{Scl}$ & GER & None & None & 267 \\
\hline 4 & $32 / \mathrm{M}$ & 25 & d-SSc & Scl70, PM/Scl, ANA & CIPO, DU, GER, ILD, PAH, My & MMF & D-penicillamine & 269 \\
\hline 5 & 49/F & 14 & Ic-SSc & ANA & GER, SRC & None & None & 293 \\
\hline 6 & $21 / F$ & 49 & Ic-SSc & Scl70, ANA & DU, GER, ILD & None & None & 302 \\
\hline 7 & $49 / F$ & 10 & d-SSc & Scl 70 & J, CIPO, DU, GER, ILD, PAH, SC & $\begin{array}{l}\text { Low-dose } \\
\text { steroids }\end{array}$ & $\begin{array}{l}\text { Bosentana, azathioprine, MTX, } \\
\text { MMF, iloprost }\end{array}$ & 319 \\
\hline 8 & $65 / F$ & 0 & Ic-SSc & Scl70, ANA & GER, ILD, PAH & None & None & 378 \\
\hline 9 & $31 / F$ & 27 & d-SSc & Scl70, SSa & DU, GER, ILD, PAH & MMF & Bosentanª, sildenafila, iloprosta ${ }^{a}$ & 390 \\
\hline 10 & $21 / F$ & 1 & Ic-SSc & ANA & DU, GER, ILD & None & Low-dose steroids & 394 \\
\hline 11 & 22/F & 7 & Ic-SSc & ANA & DU, GER, My & Ivlg & None & 508 \\
\hline 12 & $57 / F$ & 16 & Ic-SSc & Scl70, ANA & DU, GER, ILD & None & Bosentan, iloprost & 553 \\
\hline 13 & $81 / F$ & 3 & Ic-SSc & ANA & My, PAH & $\begin{array}{l}\text { Low-dose steroids, } \\
\text { Ivlg }\end{array}$ & None & 575 \\
\hline 14 & $52 / F$ & 17 & d-SSc & Scl70, ANA & J, DU, GER, ILD, SC & None & Bosentan & 613 \\
\hline 15 & $46 / F$ & 29 & Ic-SSc & $\mathrm{Cm}, \mathrm{ANA}, \mathrm{CCP}$ & GER, SC & $\begin{array}{l}\text { Low-dose steroids, } \\
\text { MTX }\end{array}$ & Leflunomide, abatacept & 677 \\
\hline 16 & $47 / F$ & 8 & d-SSc & ANA & J, DU, GER, SC, SRC & None & None & 886 \\
\hline 17 & $49 / F$ & 6 & IC-SSC & $\mathrm{Cm}, \mathrm{PM} / \mathrm{Scl}$ & DU, GER, SC & None & Bosentan ${ }^{a}$ & 1,248 \\
\hline
\end{tabular}

All patients presented with Raynaud phenomenon and were treated with symptomatic treatments (calcium channel blockers, proton pump inhibitors).

ANA, antinuclear antibody; AOPP, advanced oxidation protein products; CCP, anticyclic citrullinated peptide; CIPO, chronic intestinal pseudo-obstruction; Cm, anticentromere antibody; d-SSC, diffuse systemic sclerosis; DU, digital ulcers; F, female; GER, gastroesophageal reflux; ILD, interstitial lung disease; IVIg, intravenous immunoglobulins; J, joints; Ic-SSc, limited cutaneous systemic sclerosis; M, male; MMF, mycophenolate mofetil; MTX, methotrexate; My, myositis; PAH, pulmonary arterial hypertension; Scl70, anti-SCl70 antibody; SC, subcutaneous calcinosis; SRC, scleroderma renal crisis; SSa, anti-Ro/SSa antibody; SSC, systemic sclerosis.

Other treatment at sampling time. 
Annexin V and 7-AAD antibodies (BD Biosciences) for $15 \mathrm{~min}$ at room temperature. The labeled cells were analyzed using a FACSCanto cytometer and the BD FACSDiva ${ }^{\mathrm{TM}}$ software V.6.1.3 (BD Biosciences). Results were expressed as the percentage of Annexin $\mathrm{V}^{+}$and $7-\mathrm{AAD}^{-}$cells or gene expression fold change \pm SEM and normalized to 1 for MSCs cultured in control SAB.

\section{Senescence Assay}

MSCs were plated at 8,000 cells $/ \mathrm{cm}^{2}$ in 12 -well plates for senescence-associated $\beta$-galactosidase (SA- $\beta$-gal) staining or 10,000 cells $/ \mathrm{cm}^{2}$ in 6-well plates for quantitative assay and cultured in proliferative medium containing $5 \%$ human serum $\left(\mathrm{SAB}, \mathrm{SAB}_{400}, \mathrm{SAB}_{1000}, \mathrm{SAB}_{\mathrm{H} 2 \mathrm{O} 2}\right.$, or PS). For senescence-associated $\beta$-galactosidase (SA- $\beta$-gal) staining, cells were fixed with $2.5 \%$ glutaraldehyde for $10 \mathrm{~min}$ and incubated in staining solution at $37^{\circ} \mathrm{C}$ overnight. Staining solution consisted of $5 \mathrm{mM}$ potassium ferrocyanide, $5 \mathrm{mM}$ potassium ferricyanide, $1 \mathrm{mg} / \mathrm{mL}$ Xgal (Promega), $40 \mathrm{nM}$ citric acid/sodium phosphate ( $\mathrm{pH}$ 6), $0.15 \mathrm{M} \mathrm{NaCl}, 20 \mathrm{mM} \mathrm{MgCl}_{2}$, and $\mathrm{pH}$ was adjusted between 5.9 and 6.1. For quantitative evaluation of senescence, 15,000 cells were assayed using the Quantitative Cellular Senescence Assay Kit (Cells Biolabs, Clinisciences). Results were expressed as the relative fluorescence unit (RFU) or gene expression fold change \pm SEM and normalized to 1 for MSCs cultured in control SAB.

\section{ROS Quantification}

Quantification of ROS and nitric oxide (NO) production was performed using 6-carboxy-2',7'-dichlorodihydrofluorescein diacetate (DCFDA; ref C2938) and 4-amino-5-methylamino$2^{\prime}, 7^{\prime}$-difluorofluorescein diacetate (DAF-FM; ref D23844) probes, respectively, following supplier's recommendations (Molecular Probes, ThermoFisher Scientific). Briefly, MSCs were plated at $50,000 / \mathrm{cm}^{2}$ in six-well plates in proliferative medium and incubated with $50 \mu \mathrm{M}$ of DCFDA or $10 \mu \mathrm{M}$ of DAF2 at $37^{\circ} \mathrm{C}$ for $60 \mathrm{~min}$. Probes were then washed out with PBS. Media containing $5 \%$ human serum $\left(\mathrm{SAB}, \mathrm{SAB}_{400}, \mathrm{SAB}_{1000}, \mathrm{SAB}_{\mathrm{H} 2 \mathrm{O}}\right.$, or PS) were added for $24 \mathrm{~h}$. Fluorescence was read at different time points using a Varioskan fluorometer (ThermoFisher Scientific) at $495 \mathrm{~nm}$ for excitation and $515 \mathrm{~nm}$ emission. Results were expressed as the relative fluorescence unit (RFU) or gene expression fold change \pm SEM and normalized to 1 for MSCs cultured in control SAB.

\section{Differentiation Assays Adipogenesis}

MSCs were plated at 9,000 cells $/ \mathrm{cm}^{2}$ in six-well plates and cultured in proliferative medium containing 10\% FCS for 5 days. Differentiation media were DMEM-F12 (Lonza) with $100 \mu \mathrm{g} / \mathrm{mL}$ penicillin/streptomycin, $16 \mu \mathrm{M}$ biotin, $18 \mu \mathrm{M}$ panthotenic acid, $100 \mu \mathrm{M}$ ascorbic acid, $60 \mu \mathrm{M}$ indomethacin, $450 \mu \mathrm{M}$ isobutylmethylxanthine, $1 \mu \mathrm{M}$ dexamethasone, $1 \mu \mathrm{M}$ rosiglitazone, and $5 \%$ human serum $\left(\mathrm{SAB}, \mathrm{SAB}_{400}, \mathrm{SAB}_{1000}\right.$, $\mathrm{SAB}_{\mathrm{H} 2 \mathrm{O} 2}$, or PS). At day 21, cells were lyzed in RLT buffer for RT-qPCR or fixed with $2.5 \%$ glutaraldehyde, and lipid vacuoles were stained using Oil red $\mathrm{O}$.

\section{Chondrogenesis}

Chondrogenic differentiation of MSCs was induced by 21-day culture in micropellets. Briefly, 250,000 cells were pelleted by centrifugation in $15-\mathrm{mL}$ conical tubes and cultured in DMEM (Lonza) supplemented with $100 \mu \mathrm{g} / \mathrm{mL}$ penicillin/streptomycin, $0.35 \mathrm{mM}$ proline, $0.1 \mu \mathrm{M}$ dexamethasone, $0.17 \mathrm{mM}$ ascorbic acid2-phosphate, $1 \mathrm{mM}$ pyruvate sodium, $1 \%$ insulin-transferrinselenic acid (ITS) (Lonza), $10 \mathrm{ng} / \mathrm{mL}$ TGF- $\beta 3$ (R\&D Systems), and $5 \%$ human serum $\left(\mathrm{SAB}, \mathrm{SAB}_{400}, \mathrm{SAB}_{1000}, \mathrm{SAB}_{\mathrm{H} 2 \mathrm{O}}\right.$, or $\left.\mathrm{PS}\right)$. At day 21 , micropellets were lyzed in RLT buffer and stored at $-80^{\circ} \mathrm{C}$.

\section{Osteogenesis}

MSCs were plated at 3,000 cells $/ \mathrm{cm}^{2}$ in six-well plates and cultured in differentiation medium: DMEM (Lonza) with $10 \mathrm{mM}$ $\beta$-glycerophosphate, $0.1 \mu \mathrm{M}$ dexamethasone, $70 \mu \mathrm{M}$ ascorbic acid2-phosphate, $100 \mu \mathrm{g} / \mathrm{mL}$ penicillin/streptomycin, and 5\% human serum ( $\mathrm{SAB}, \mathrm{SAB}_{400}, \mathrm{SAB}_{1000}, \mathrm{SAB}_{\mathrm{H} 2 \mathrm{O} 2}$, or PS). At day 21 , cells were lyzed in RLT buffer and stored at $-80^{\circ} \mathrm{C}$ or fixed with $95 \%$ ethanol, and mineralization was observed after Alizarin Red S staining.

\section{RNA Extraction and RT-qPCR}

RNA was extracted using the RNeasy mini kit (Qiagen) following the supplier's recommendations. RNA (400 ng) was reverse transcribed using the Moloney Murine Leukaemia Virus Reverse Transcriptase (M-MLV) enzyme (Invitrogen, ThermoFisher Scientific). qPCR was then performed on $20 \mathrm{ng}$ of cDNA using SybrGreen ${ }^{\circledR}$ PCR Master Mix (Roche) with specific primers (Table $\mathrm{S} 1$ in Supplementary Material). PCR reaction was performed as follows: $95^{\circ} \mathrm{C}$ for $5 \mathrm{~min} ; 40$ cycles at $95^{\circ} \mathrm{C}$ for $15 \mathrm{~s} ; 64^{\circ} \mathrm{C}$ for $10 \mathrm{~s}$, and $72^{\circ} \mathrm{C}$ for $20 \mathrm{~s}$ in a LightCycler 480 instrument (Roche Diagnostics) or ViiA ${ }^{\mathrm{TM}} 7$ Real-Time PCR System (Applied Biosystems, ThermoFisher Scientific). All values were normalized on RPS9 housekeeping gene and expressed as fold change using the formulae $2^{-\Delta \Delta \mathrm{Ct}}$.

\section{T Lymphocyte Proliferative Assay}

MSCs were cultured in proliferative medium containing 5\% human serum ( $\mathrm{SAB}, \mathrm{SAB}_{400}, \mathrm{SAB}_{1000}, \mathrm{SAB}_{\mathrm{H} 2 \mathrm{O} 2}$, or PS) for 3 days. They were then trypsinized and plated with $2 \times 10^{5} \mathrm{PBMC}$ at different densities to get ratios of $1 / 5,1 / 10$, and 1/50 (MSC/PBMC) in 96-well plates. Cells were cultured in IMDM (Invitrogen) containing $10 \%$ heat inactivated FCS, $100 \mu \mathrm{g} / \mathrm{mL}$ penicillin/ streptomycin, $2 \mathrm{mM}$ glutamine, $0.1 \mathrm{mM}$ non-essential amino acids, $5 \times 10^{5} \mathrm{M} 2$-mercaptoethanol, $1 \mathrm{mM}$ sodium pyruvate, $10 \%$ FCS, $25 \mathrm{mM}$ HEPES, and $2.5 \mu \mathrm{g} / \mathrm{mL}$ phytohemaglutinin (Sigma) for T lymphocyte activation. After 3 days, T lymphocyte proliferation was measured with Cell Proliferation ELISA, BrdU assay (Sigma-Aldrich). Results were expressed as the percentage of proliferation \pm SEM and normalized at $100 \%$ for proliferation of activated PBMC minus basal proliferation.

\section{Statistical Analyses}

Statistical analysis was performed with GraphPad 6 Prism Software. Data were compared using the Mann-Whitney test for non-parametric values. A $p$ value $<0.05$ was considered significant. 


\section{RESULTS}

\section{High AOPP Levels in SSc Patient Serum Affected the Proliferation Rate of MSC}

We first evaluated the proliferation rate of MSCs cultured for 10 days in medium containing $5 \%$ serum from healthy patients (SAB) or oxidized $\mathrm{SAB}$ that has been submitted to $\mathrm{H}_{2} \mathrm{O}_{2}\left(\mathrm{SAB}_{\mathrm{H} 2 \mathrm{O} 2}\right)$ or $\mathrm{HOCl}$ treatment to get 400 or $1,000 \mu \mathrm{mol} / \mathrm{L}$ of $\mathrm{AOPP}\left(\mathrm{SAB}_{400}\right.$ and $\mathrm{SAB}_{1000}$ ). In $\mathrm{SAB}, \mathrm{MSC}$ rapidly proliferated during the first
3 days and then weakly proliferated till day 10 (Figure 1A). By contrast, MSCs cultured in oxidized SAB did not proliferate compared to day 0 and even died when cultured in $\mathrm{SAB}_{\mathrm{H} 2 \mathrm{O} 2}$. By comparison with MSCs cultured in SAB, growth of MSCs in oxidized $\mathrm{SAB}$ was significantly inhibited at whatever the time point, indicating that oxidized human serum inhibited MSC proliferation.

We also investigated the growth rate of MSCs cultured with SSc patient serum (PS). MSCs cultured with PS ( $\left.\mathrm{PS}_{\text {pool }}\right)$ did not
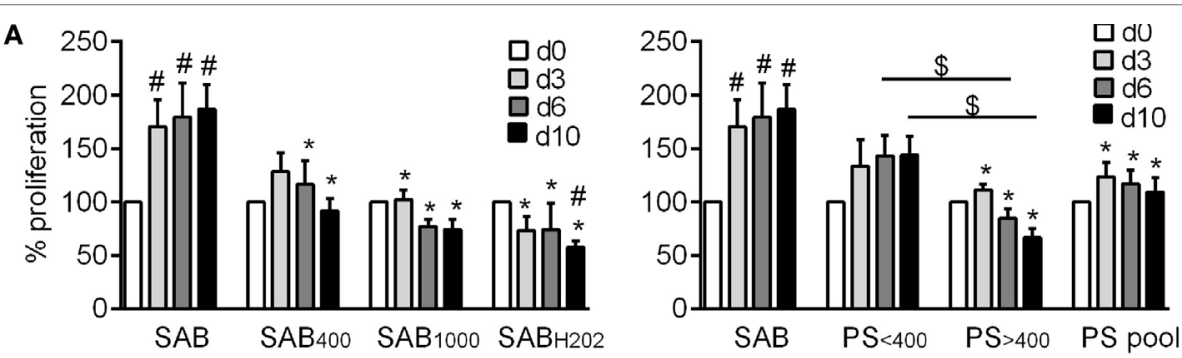

B

C
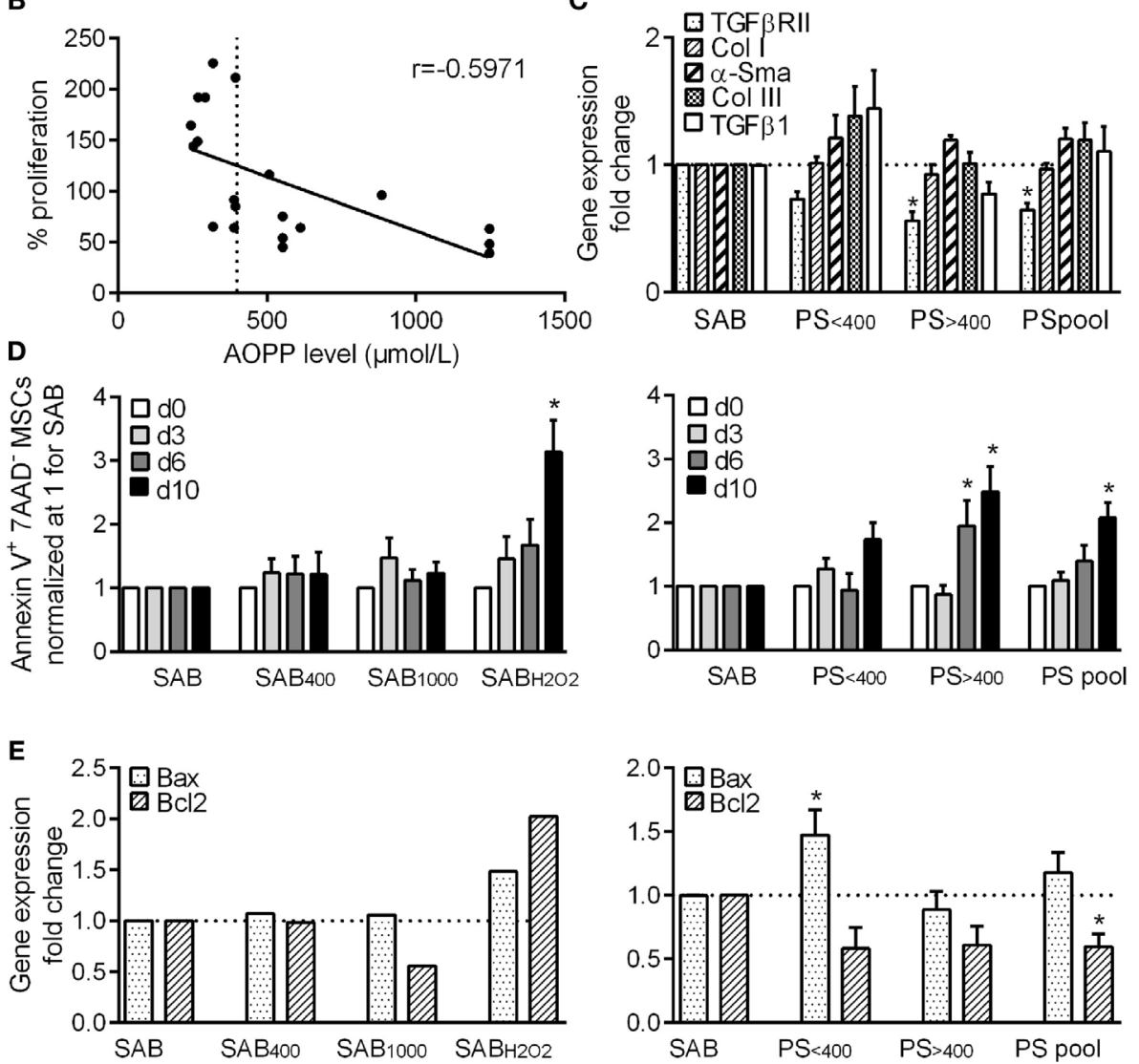

FIGURE 1 | $\mathrm{HOCl}$ - or $\mathrm{H}_{2} \mathrm{O}_{2}$-induced serum AOPPs and systemic sclerosis (SSc) patient serum decreased the proliferation rate of MSCs and increased the number of apoptotic MSCs. (A) Percentage of MSC proliferation depending on the concentration of advanced oxidation protein products (AOPP) induced by HOCl in human serum $\mathrm{AB}(\mathrm{SAB}): 400 \mu \mathrm{mol} / \mathrm{L}\left(\mathrm{SAB}_{400}\right)$ or $1,000 \mu \mathrm{mol} / \mathrm{L}\left(\mathrm{SAB}_{10000}\right), \mathrm{H}_{2} \mathrm{O}_{2}\left(\mathrm{SAB}_{\mathrm{H} 202}\right)(n=8)$, or SSc patient serum at different time points: day 3, 6, and 10. Patient serum (PS) were divided in two groups depending on AOPP levels: $<400 \mu \mathrm{mol} / \mathrm{L}\left(\mathrm{PS}_{<400} ; n=11\right)$ or $>400 \mu \mathrm{mol} / \mathrm{L}\left(\mathrm{PS}_{>400} ; n=9\right)$ or pooled in a single group $\left(\mathrm{PS}_{\text {pool}}\right.$; $n=20$ ). Data were normalized to $100 \%$ of cells plated at day 0. (B) Linear regression curve between percentage of MSC proliferation and AOPP level in SSc patient serum at day $10(n=20)$. $r$ indicated the Pearson's correlation coefficient. (C) Gene expression fold change of different profibrotic markers $\left(P S_{400}\right.$ and PS $>400, n=4$; $\left.\mathrm{PS}_{\text {pool }}, n=8\right)$. (D) Percentage of Annexin $\mathrm{V}^{+}$7-AAD apoptotic MSCs at different time points $(n=8)$. (E) Gene expression fold change of proapoptotic marker Bax or antiapoptotic marker Bcl2 ( $\mathrm{PS}_{<400}$ and $\mathrm{PS}_{>400}, n=4 ; \mathrm{PS}_{\mathrm{pool}}, n=8$ ). Data were normalized to 1 for MSCs in SAB-containing medium. \#p $<0.05$ versus day 0 ; ${ }^{*} p<0.05$ versus $\mathrm{SAB}$ at same time point; $\$ p<0.05$ versus indicated condition. 
proliferate compared to day 0 , and proliferation was significantly inhibited compared to MSC in SAB-containing medium at each time point (Figure 1A). However, we noticed some differences according to the level of AOPP measured in SSc serum and segregated the data in two groups: serum with AOPP levels less than or more than $400 \mu \mathrm{mol} / \mathrm{L}\left(\mathrm{PS}_{<400}\right.$ or $\mathrm{PS}_{>400}$, respectively). The median AOPP level in PS was $390 \mu \mathrm{mol} / \mathrm{L}$. Proliferation of MSCs cultured with $\mathrm{PS}_{<400}$ was not different from MSCs cultured with SAB, whereas proliferation of MSCs cultured with $\mathrm{PS}_{>400}$ was significantly inhibited and lower than that of MSCs cultured with $\mathrm{PS}_{<400}$ at all time points. Indeed, a negative linear correlation between the proliferation rate of MSCs and AOPP levels was found with a significant Pearson's correlation coefficient $r$ of -0.5971 ( $p=0.0054$ ) (Figure 1B). This could not be attributed to variability between MSC samples because proliferation rates of different MSC samples cultured with same patient serum were similar (data not shown). Finally, expression levels of five genes associated with SSc phenotype did not change (Figure 1C). Indeed, long-term exposure to high levels of AOPP and oxidative stress inhibited MSC proliferation but did not change the phenotype of MSCs.

\section{High AOPP Levels in Patient Serum Induced MSC Apoptosis}

We also found that the percentage of apoptotic MSCs in control SAB was $5.33 \pm 1.60 \%$ at day $3,7.34 \pm 1.77 \%$ at day 6 , and $5.19 \pm 1.17 \%$ at day 10 . By comparison, no increase of apoptosis was noticed when MSCs were cultured with $\mathrm{SAB}_{400}$, $\mathrm{SAB}_{1000}$, or $\mathrm{SAB}_{\mathrm{H} 2 \mathrm{O} 2}$ at day 3 or 6 (Figure 1D). At day 10 , the percentage of apoptotic MSCs was significantly increased with $\mathrm{SAB}_{\mathrm{H} 2 \mathrm{O} 2}$, which mirrored the lower proliferation rate of MSCs observed in Figure 1A. When MSCs were cultured with PS, the percentage of apoptotic cells was significantly increased at days 6 and 10 for MSCs expanded with $\mathrm{PS}_{>400}$ and $\mathrm{PS}_{\text {pool }}$ (Figure 1D). Expression levels of the pro-apoptotic marker Bax was increased with $\mathrm{PS}_{<400}$, and the antiapoptotic marker Bcl2 was significantly decreased (Figure 1E). Culture of MSCs with $\mathrm{H}_{2} \mathrm{O}_{2}$ or PS therefore induced a slight increase of apoptosis on the long term.

\section{Low AOPP Levels in Patient Serum Induced MSC Senescence}

We also assessed senescence by quantifying SA- $\beta$-gal activity of MSCs. In the SAB culture condition, we measured $143.7 \pm 20.4$ at day $3,199.3 \pm 23$ at day 6 , and $258 \pm 80 \mathrm{RFU}$ at day 10 that was normalized to 100 at each time point. Compared to SAB, SA- $\beta$-gal activity of MSCs was increased when cultured with $\mathrm{SAB}_{1000}$ or $\mathrm{SAB}_{\mathrm{H} 2 \mathrm{O} 2}$ although significance was reached only at day 3 (Figure 2A). A significant increase of SA- $\beta$-gal activity was observed only for MSCs cultured with $\mathrm{PS}_{<400}$ and $\mathrm{PS}_{\text {pool }}$ at day 6 . Qualitative assessment by SA- $\beta$-gal staining reflected quantitative analysis (Figure 2B). Expression levels of the senescent markers p16, p21, and p27 were increased when MSCs were cultured with $\mathrm{PS}_{<400}$ and $\mathrm{PS}_{\text {pool }}$ (Figure 2C). Altogether, the data pointed out induction of senescence in MSCs by oxidative stress $\left(\mathrm{SAB}_{1000}\right.$ or $\mathrm{H}_{2} \mathrm{O}_{2}$ ) and $\mathrm{PS}_{<400}$.

\section{Patient Serum Did Not Induce Oxidative Stress in MSCs}

We next measured the production of reactive oxygen and nitrogen species (ROS and RNS, respectively). MSCs cultured with $\mathrm{SAB}_{400}, \mathrm{SAB}_{1000}$, or $\mathrm{PS}_{<400}$ produced higher levels of $\mathrm{NO}$ than MSCs in SAB (Figure 3A), whereas $\mathrm{PS}_{>400}$ and $\mathrm{PS}_{\text {Pool }}$ did not significantly modify $\mathrm{NO}$ secretion. When looking at ROS production, $\mathrm{SAB}_{1000}$ and $\mathrm{SAB}_{\mathrm{H} 2 \mathrm{O} 2}$ induced a significant increase of ROS production by MSCs, while PS did not alter ROS production (Figure 3B). We also noticed that the superoxide dismutase (Sod)2 antioxidant gene was increased in MSCs cultured with PS, whatever the AOPP levels, correlating the absence of ROS production (Figure 3C). Indeed, PS did not influence the production of RNS or ROS by MSCs but significantly increased expression of Sod2, suggesting a possible induction of antioxidative activity.

\section{Patient Serum Increased the Differentiation Capacities of MSCs toward Adipocytes and Osteoblasts}

We then assessed the capacity of MSCs to give rise to chondrocytes. Differentiation with SAB-containing inductive medium was confirmed by increased levels of sex-determining region Y-box9 (SOX9), aggrecan, type II collagen variant B (COL2a1 $\Delta 2)$ (5.7-, 7.7-, and 622-fold factor, respectively). Compared to SAB, oxidized SAB or SSc PS added in the inductive medium did not impact chondrogenic differentiation (Figure 4A). Variability between MSC-PS combinations was noticed but not related to AOPP levels or MSC samples.

Adipogenic differentiation of MSCs occurred in SABcontaining inductive medium as assessed by Oil red $\mathrm{O}$ staining (Figure 4B) and increased levels of all tested markers: lipoprotein lipase, peroxisome proliferator-activator receptor- $\gamma$, fatty acid binding protein 4 (11,307-, 594-, and 8.8-fold factor, respectively). When compared to $\mathrm{SAB}$, MSCs cultured with $\mathrm{SAB}_{400}, \mathrm{SAB}_{1000}$, $\mathrm{SAB}_{\mathrm{H} 2 \mathrm{O} 2}$, or PS tended to exhibit higher levels of differentiation markers (Figure 4C). Again, high variability between combinations of MSC-PS was observed but not related to AOPP levels or MSC samples.

Finally, in SAB-containing medium, MSCs expressed higher levels of Runt-related transcription factor (Runx)2, alkaline phosphatase, and type I collagen (Col I) (3-, 69-, and 2-fold factor, respectively) compared to proliferative conditions. Similar increase of osteogenic markers was observed when MSCs were cultured with $\mathrm{SAB}_{400}, \mathrm{SAB}_{1000}$, and $\mathrm{SAB}_{\mathrm{H} 2 \mathrm{O} 2}$ although Alizarin red $S$ and AP staining were higher (Figures $4 \mathrm{D}-\mathrm{F}$ ). By contrast, expression of two out of three osteogenic markers, Runx2 and Col I, were significantly enhanced by MSCs cultured with PS. These data indicated that SSc serum increased the osteogenic differentiation potential of MSCs.

\section{Patient Serum Reduced the Immunosuppressive Capacities of MSCs}

Finally, we investigated the immunosuppressive potential of MSCs when cultured with oxidized SAB or PS. A dosedependent immunosuppressive potential was shown with MSCs precultured with SAB or oxidized SABs, except for MSCs with 

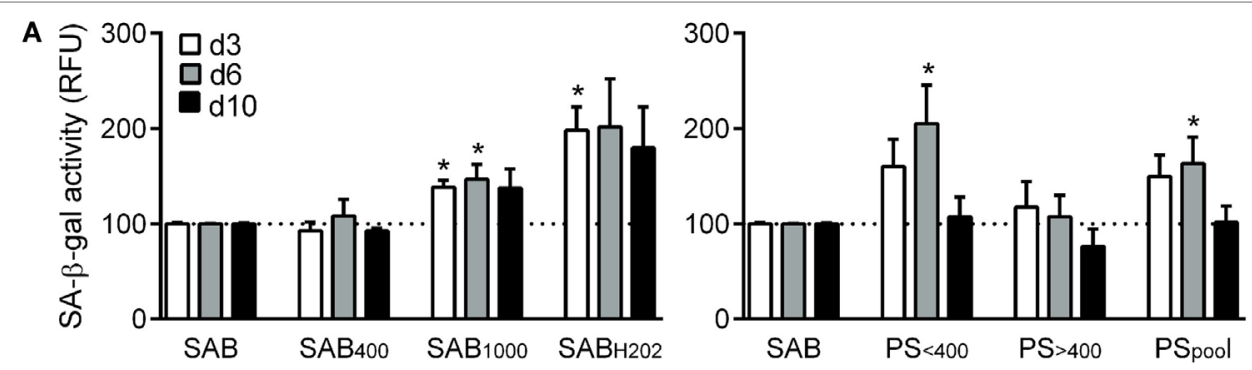

B
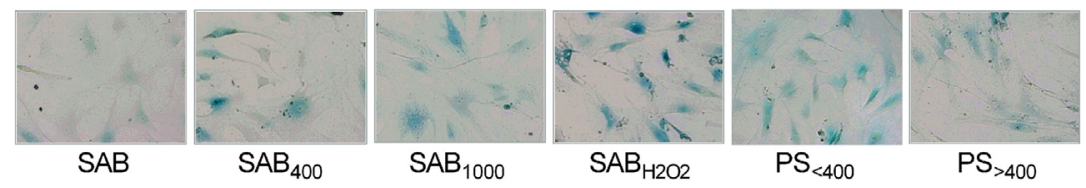

C
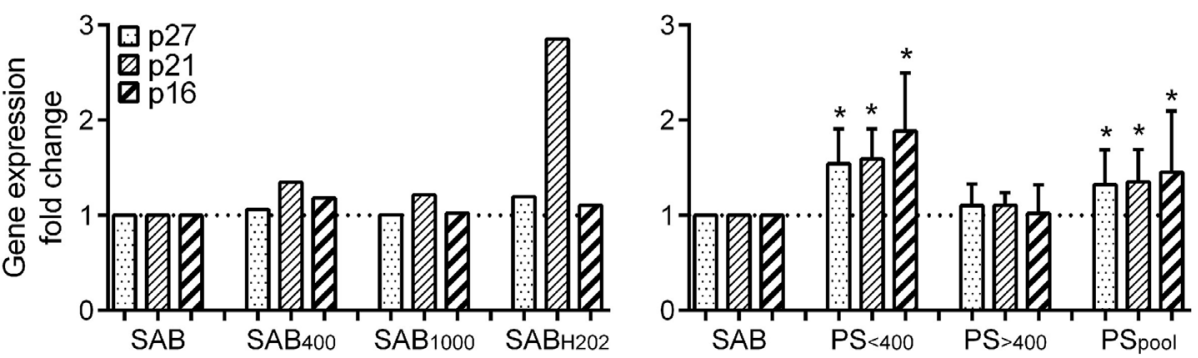

FIGURE 2 | $\mathrm{HOCl}$ - or $\mathrm{H}_{2} \mathrm{O}_{2}$-induced serum AOPPs and systemic sclerosis (SSc) patient serum increased the number of senescent MSCs. (A) quantification of

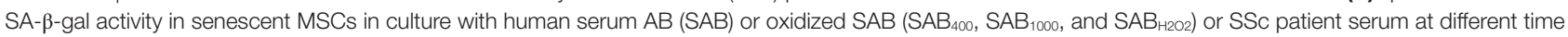
points: day 3, 6 , or $10(n=8)$. Senescence was measured using the quantitative cellular senescence assay kit (Cells Biolabs) and expressed as relative fluorescence unit (RFU). Sera from patient (PS) were divided in two groups depending on AOPP levels: $<400 \mu \mathrm{mol} / \mathrm{L}$ (PS $<400 ; n=11)$ or $>400 \mu \mathrm{mol} / \mathrm{L}$ (PS $>400 ; n=9)$ or pooled in a single group (PS pool; $n=20$ ). Data were normalized to 100 for senescent MSCs detected in SAB-containing medium. (B) Representative photographs of SA- $\beta$-gal staining of MSCs cultured in same conditions as in (A), at day 6. (C) Gene expression fold change of different senescence markers: p16, p21, and p27 in same conditions as in (A) $\left(\mathrm{PS}_{<400}\right.$ and $\mathrm{PS}_{>400}, n=4$; $\left.\mathrm{PS}_{\mathrm{poo}}, n=8\right)$. Data were normalized to 1 for apoptotic MSCs detected in $\mathrm{SAB}-\mathrm{containing}$ medium. ${ }^{*} p<0.05$ versus $\mathrm{SAB}$ at same time point.

$\mathrm{SAB}_{\mathrm{H} 2 \mathrm{O} 2}$ at $1 \mathrm{MSC} / 10 \mathrm{PBMC}$ ratio (Figure 5). By contrast, MSCs cultured with PS exerted a lower immunosuppressive potential as observed at the $1 \mathrm{MSC} / 10 \mathrm{PBMC}$ ratio. This effect was mostly attributed to the $\mathrm{PS}_{<400}$ group of patients. The present data highlighted a reduced immunosuppressive potential of MSCs when cultured with SSc PS.

\section{DISCUSSION}

Some previous studies focused on the characteristics of SSc-MSCs for their possible therapeutic use for treating patients suffering from the most severe forms of SSc (13). However, to our knowledge, this is the first study evaluating the functional capacity of heterologous MSCs obtained from non-SSc donors when exposed to the oxidative environment encountered in patients, namely SSc serum. This study aimed at investigating MSC properties in this specific context of allogeneic transplantation.

Herein, we observed that oxidative stress and AOPP levels in SSc patient serum impacted the functional properties of MSCs by reducing their proliferation and immunosuppressive potentials, while apoptosis, senescence, and differentiation potential were increased. The role of ROS and $\mathrm{H}_{2} \mathrm{O}_{2}$ on proliferation, self-renewal, and senescence of MSCs has already been reported
$(14,15)$. Our results are in line with previous studies on resident SSc-MSCs, which exhibited modifications of their functions and features: early senescence with higher telomerase activity, reduced proliferative activity, and even increased expression of TGF- $\beta$-RII, leading to increased sensibility to TGF- $\beta$ and excessive production of type I collagen $(6,7)$. SSc-associated oxidative environment reduced proliferation rate and survival of resident MSCs and therefore might impact heterologous MSCs after implantation in patients. In our conditions, proliferation rates were negatively correlated with AOPP levels. Indeed, in a perspective of MSC-based therapy in SSc, it could be tempting to propose MSC infusion in patients with low AOPP levels. Of importance, the percentage of apoptotic cells was inversely related to proliferation and significantly increased at day 10 of culture. The number of senescent MSCs also increased in contact of SSc serum at day 6, and no senescence was observed at day 10. Decreased proliferation was therefore likely associated with a first phase of senescence followed by a second phase of apoptosis. Both processes were not observed earlier, indicating that continuous exposure to oxidative stress was required to reduce MSC survival. In a therapeutic setting, the oxidative environment of SSc serum will likely not affect survival of heterologous MSCs since the half-life of MSCs in the bloodstream is less than 

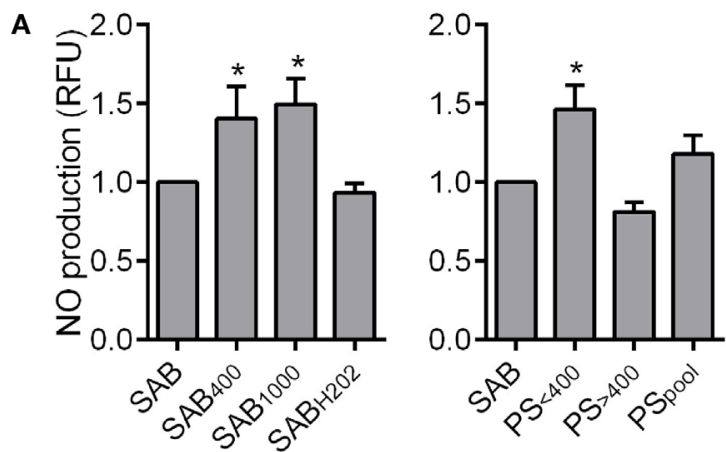

B
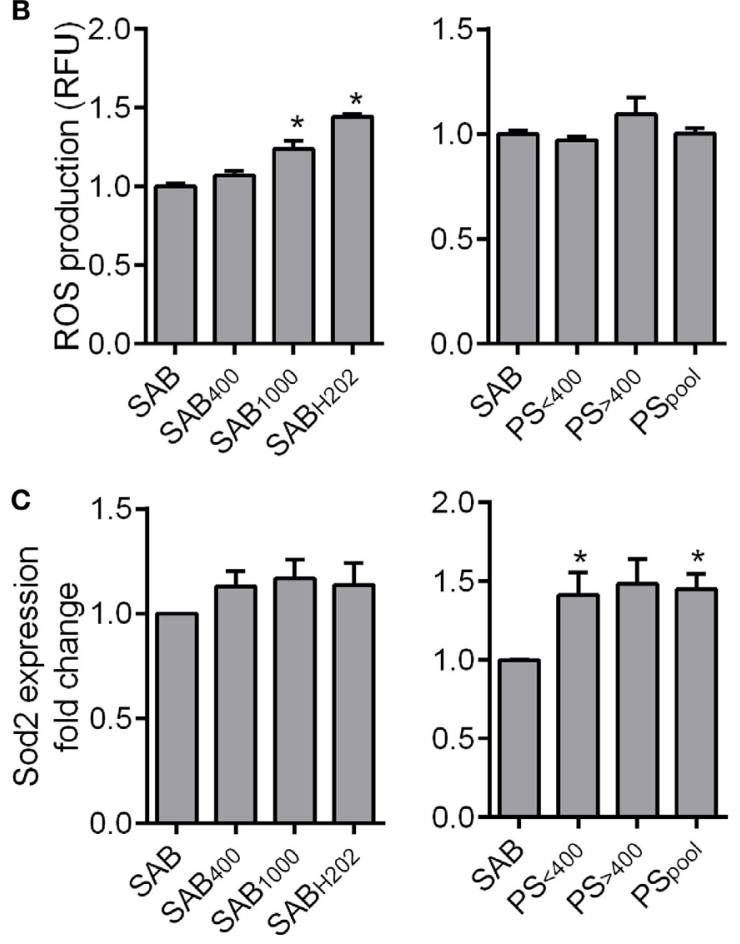

FIGURE 3 | $\mathrm{HOCl}$ - or $\mathrm{H}_{2} \mathrm{O}_{2}$-induced serum AOPPs increased nitric oxide (NO) and reactive oxygen species (ROS) production in MSCs. (A) Quantification of NO production in MSCs in culture with human serum AB $(\mathrm{SAB})$ or oxidized $\mathrm{SAB}\left(\mathrm{SAB}_{400}, \mathrm{SAB}_{1000}\right.$, and $\mathrm{SAB}_{\mathrm{H} 2 \mathrm{O} 2} ; n=7$ for each condition) or SSc patient serum at $24 \mathrm{~h}$. Sera from patient (PS) were divided in two groups depending on AOPP levels: $<400 \mu \mathrm{mol} / \mathrm{L}\left(\mathrm{PS}_{<400} ; n=9\right)$ or $>400 \mu \mathrm{mol} / \mathrm{L}\left(\mathrm{PS}_{>400} ; n=7\right)$ or pooled in a single group ( $\left.\mathrm{PS}_{\mathrm{pool}} ; n=16\right)$. NO production was measured using 4-amino-5-methylamino-2', $7^{\prime}$ difluorofluorescein diacetate probes (Molecular Probes, ThermoFisher Scientific). (B) Quantification of ROS production in MSCs in same conditions as in (A). ROS production was measured using 6-carboxy-2', $7^{\prime}$ -

dichlorodihydrofluorescein diacetate probes (Molecular Probes, ThermoFisher Scientific). (C) Gene expression fold change of Sod2 antioxidant marker in same conditions as in (A) PS $_{<400}$ and $\mathrm{PS}_{>400}, n=4$; $\left.\mathrm{PS}_{\text {pool }}, n=8\right)$. Data were normalized to 1 for MSCs in SAB-containing medium. ${ }^{*} p<0.05$ versus SAB at same time point.

$24 \mathrm{~h}$, and the majority of cells disappeared within few days (16). Of interest, even though a study reported that coculture of SSc endothelial cells with MSCs induced the expression of myofibroblastic markers by MSCs, culture with SSc serum did not change the phenotype of MSCs (17).

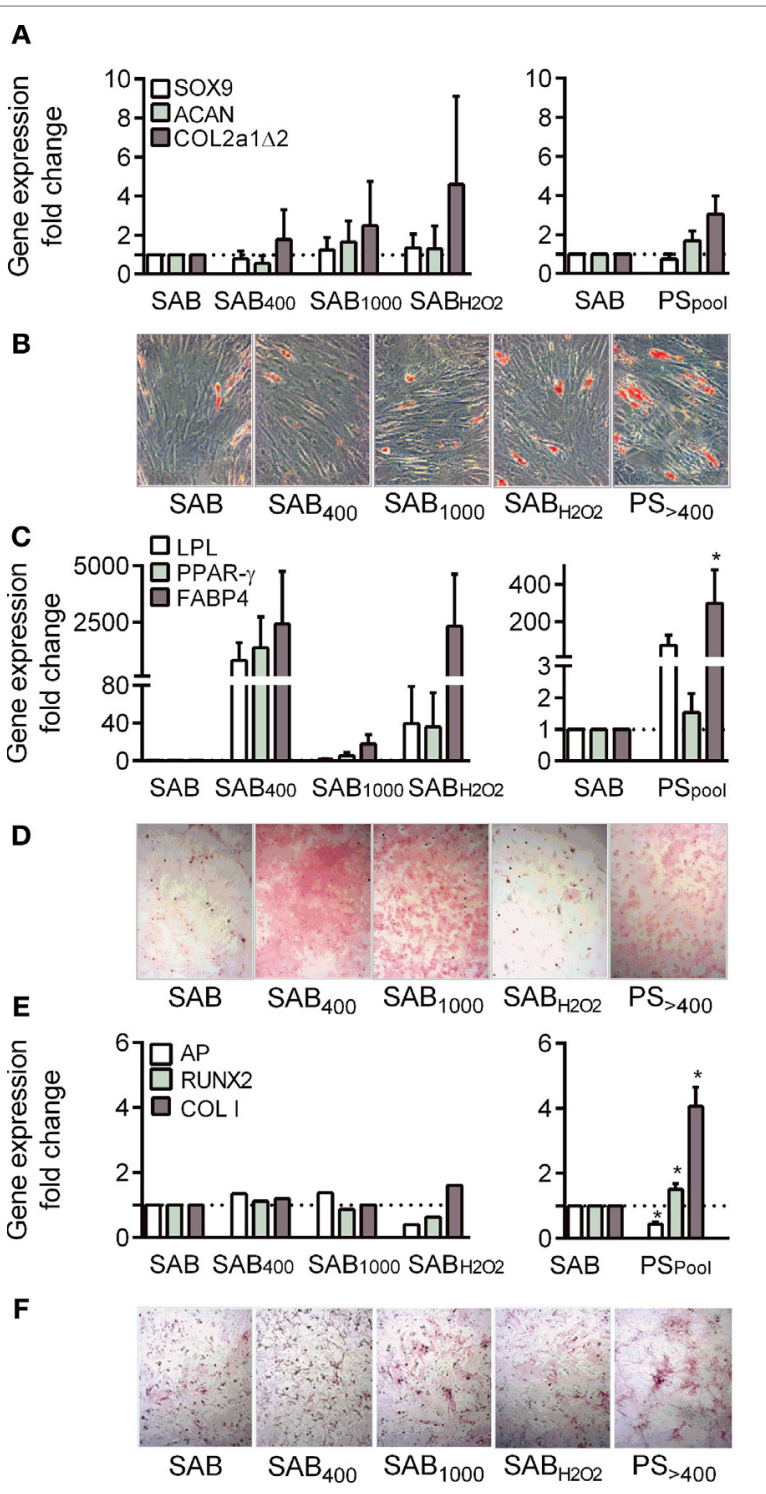

FIGURE 4 | Systemic sclerosis (SSc) patient serum increased osteogenic differentiation potential of MSCs. (A) Chondrogenic differentiation of MSCs cultured with human serum $\mathrm{AB}(\mathrm{SAB})$ or oxidized $\mathrm{SAB}\left(\mathrm{SAB}_{400}, \mathrm{SAB}_{1000}\right.$, and $\mathrm{SAB}_{\mathrm{H}_{2} \mathrm{O} 2} ; n=3$ for each condition) or SSc patient serum $(n=13)$ at day 21. Chondrogenesis was assessed by measuring expression level of specific genes: sex-determining region Y-box9 (SOX9), aggrecan (ACAN), and type ॥ collagen variant B (COL2a1 $\Delta 2$ ) by RT-qPCR. (B) Representative photographs of MSCs depicted in (C) and stained with Oil Red O. (C) Adipogenic differentiation of MSCs cultured with human SAB or oxidized SAB $\left(\mathrm{SAB}_{400}\right.$, $\mathrm{SAB}_{1000}$, and $\mathrm{SAB}_{\mathrm{H} 2 \mathrm{O} 2} ; n=3$ for each condition) or SSc patient serum $(n=13)$ at day 21. Adipogenesis was assessed by measuring expression level of specific genes: lipoprotein lipase (LPL), peroxisome proliferatoractivator receptor (PPAR)- $\gamma$, and fatty acid binding protein (FABP) 4 by RT-qPCR. (D) Representative photographs of MSCs depicted in (E) and stained with Alizarin Red S. (E) Osteogenic differentiation of MSCs cultured with human $\mathrm{SAB}$ or oxidized $\mathrm{SAB}\left(\mathrm{SAB}_{400}, \mathrm{SAB}_{1000}\right.$, and $\mathrm{SAB}_{\mathrm{H} 2 \mathrm{O} 2} ; n=3$ for each condition) or SSc patient serum $(n=13)$ at day 21. Osteogenesis was assessed by measuring expression level of specific genes: Runt-related transcription factor (Runx)2, alkaline phosphatase (AP), and type I collagen (Col I) by RT-qPCR. (F) Representative photographs of MSCs depicted in (E) and stained for AP detection. Data were normalized to 1 for MSCs in SAB-containing medium. ${ }^{*} p<0.05$ versus SAB at same time point. 

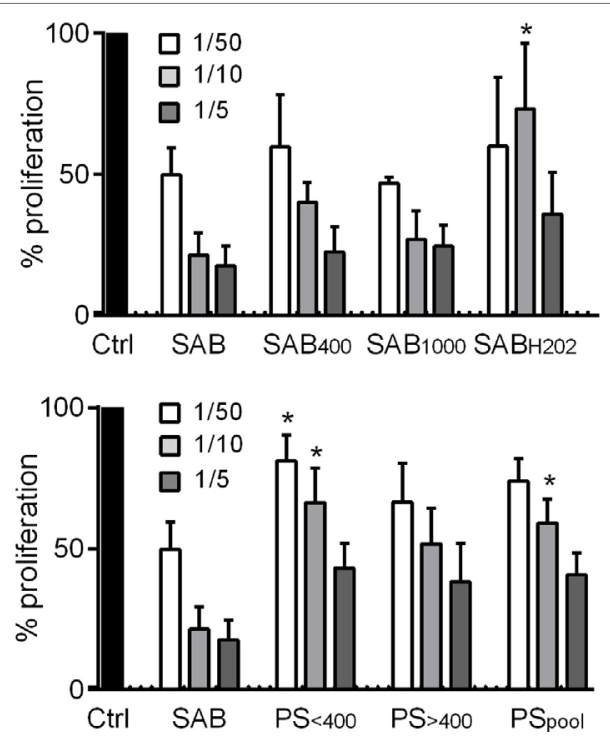

FIGURE 5 | Systemic sclerosis (SSc) patient serum decreased the immunosuppressive potential of MSCs. Percentage of T lymphocyte proliferation when cultured alone (Ctrl; normalized to 100\%) or with different ratios of MSCs (1/50; 1/10; $1 / 5 \mathrm{MSC} / \mathrm{T}$ lymphocyte ratios) that were precultured for 3 days with human serum $A B(S A B)$ or oxidized $S A B\left(S A B B_{400}\right.$, $\mathrm{SAB}_{1000}$, and $\mathrm{SAB}_{\mathrm{H}_{2} \mathrm{O} 2} ; n=3$ for each condition) or SSc patient serum. Sera from patient (PS) were divided in two groups depending on AOPP levels: $<400 \mu \mathrm{mol} / \mathrm{L}\left(\mathrm{PS}_{<400} ; n=6\right)$ or $>400 \mu \mathrm{mol} / \mathrm{L}\left(\mathrm{PS}_{>400} ; n=6\right)$ or pooled in a single group ( $\mathrm{PS}_{\text {pool }} ; n=12$ ). T lymphocyte proliferation was measured with Cell Proliferation ELISA, BrdU assay (Sigma-Aldrich). Results were expressed as the percentage of proliferation \pm SEM. ${ }^{*} p<0.05$ versus SAB at same time point.

We also demonstrated that PS did not increase the oxidative stress in MSCs, which can be made in relation with the upregulation of SOD2 antioxidant enzyme. This is concordant with the findings that SSc-MSCs can counteract oxidative stress by improving antioxidant defenses (18) and suggests that the antioxidative functions of MSCs were preserved under SSc oxidative environment. Other factors secreted by MSCs can play a role in their antioxidant defenses such as heme oxygenase-1 (HO-1) or glutathione-disulfide reductase (GSR). No increase of these factors was detected in our conditions (data not shown). However, the operative factors produced by MSCs may vary in different experimental conditions, likely due to different levels of ROS produced (19). This may explain the absence of upregulation of HO-1 or GSR in our settings or the production of other factors that are still to be identified. This will need to be further investigated. Interestingly, NO production by MSCs was increased following incubation with intermediate and high doses of $\mathrm{HOCl}$-induced AOPPs contained in SAB, but only with intermediate doses of AOPPs contained in PS. A possible explanation could be an increased antioxidative capacity of MSCs subjected to the highest oxidative environments. However, in our conditions, both sera with low and high levels of AOPPs increased SOD2, suggesting that AOPP levels alone cannot explain this discrepancy. Indeed, PS likely conveyed both prooxidative and antioxidative components that activated the antioxidative function of MSCs. Defense against oxidative stress may also be associated to the response to DNA damage and senescence. A number of molecules are common to these processes and may be called "senescence suppressors" (20). These are promising targets for increasing cell proliferation and differentiation capacities of MSCs and also delay the onset of senescence. Treatments that could increase expression of these senescence suppressors might help MSCs maintaining or enhancing their properties and therapeutic efficacy. This is of importance for MSC-based therapy in SSc where the main effect of the treatment would be to reduce the oxidative stress contributing to the clinical manifestations of the disease.

Considering differentiation potential of MSCs, a high variability between PS was observed, while our results were quite homogenous when considering the other characteristics of MSCs, probably due to lower number of replicates. This variability was not clearly explained by individual characteristics of SSc patients (no correlation was found) or by AOPP levels. Finally, we noticed that differentiation potential of MSCs was not significantly altered, except for osteogenesis, which was increased following incubation of MSCs with PS. Previous data reported that ROS and $\mathrm{H}_{2} \mathrm{O}_{2}$ inhibited osteogenesis, but other reports showed that ROS increased calcification and osteogenesis (21). In addition, induction of osteogenesis in MSCs was associated with an upregulation of SOD2 and antioxidant enzymes but a decrease in ROS. In this study, when cultured in the presence of SSc sera PS, MSCs exhibited an increase of antioxidant capacity, which can be associated to osteogenesis, while the presence of ROS in sera could also participate to increase osteogenic differentiation potential. However, we cannot exclude the possibility that factors other than oxidative components and present in PS might impact MSC differentiation potential. With regard to adipogenesis, a ROS increase was associated with adipogenesis, and antioxidant enzymes such as SOD were upregulated during adipogenic differentiation (22). Several studies also reported the proadipogenic effect of ROS and $\mathrm{H}_{2} \mathrm{O}_{2}$ (23). In concordance with our study, some others demonstrated similar differentiation potential of SSc-MSCs and MSCs obtained from healthy donors $(9,13,24)$. Scuderi et al. also reported no alteration in phenotype, differentiation, or proliferation potentials of MSCs, which were obtained from adipose tissue of six SSc patients and compared with those from healthy donors (25). Those studies and our study might suggest that slight alterations of MSC functions may be a consequence of SSc-associated oxidative environment and related to differences in patient characteristics but not to a primitive cell dysfunction. Alterations of differentiation potential might be deleterious in the context of SSc, and enhanced osteogenic differentiation of MSCs could lead to subcutaneous calcifications in those patients. However, in hands series, no relationship was established between clinically patent subcutaneous calcifications and differentiation capacities. In addition, unwanted differentiation capacity of MSCs has been rarely if ever documented in the thousands of patients who received MSCs in clinical trials while safety of MSCs is prone. To our knowledge, no ossification was reported in patients following MSC-based treatments.

Another important finding of this study is the decreased immunosuppressive function of heterologous MSCs in the presence of PS, which was not observed in the presence of 
HOCl-induced AOPPs containing sera. Therefore, our data suggest that other components of PS likely impact on the immunomodulatory properties of MSCs. In the study by Cipriani et al., MSCs obtained from SSc patients acquired senescence characteristics, but they maintained their immunosuppressive capacities on lymphocyte proliferation (8). Similarly, another study demonstrated similar immunosuppressive functions of SScMSCs compared to MSCs obtained from healthy donors $(24,26)$. However, MSCs from patients with other diseases associated with elevated oxidative stress, such as atherosclerosis and type 2 diabetes, also exhibited reduced ability to inhibit T-cell proliferation (27). Our findings suggest that SSc oxidative environment could exert a deleterious effect on MSC immunosuppressive functions, maybe impairing efficacy of MSC transplantation in some SSc patients. The immunosuppressive capacity of MSCs strongly contributes to their therapeutic effects in autoimmune diseases (10). These effects might be important in SSc, and we recently demonstrated that the therapeutic efficacy of MSCs in the HOCl-induced murine model of SSc was mediated through the reduction of tissue inflammation resulting in fewer macrophages and T-cell infiltrates and lower levels of pro-inflammatory cytokines (5). Indeed, even in these oxidant conditions close to the human disease, MSCs were shown to be therapeutically efficient, suggesting that MSCs adapted to the environment and preserved their functionalities.

In conclusion, we showed that in the presence of oxidative environment of PS, MSCs retained their proliferative potential, survived for at least the first 3 days of exposure, and enhanced their antioxidant capacity and osteogenic potential, whereas their immunosuppressive function was reduced. These findings were globally homogenous among PS, even if clinical presentation of our patients was heterogenous. MSCs still represent a promising therapy for SSc, independently of the source (adipose tissue or

\section{REFERENCES}

1. Marie I, Gehanno JF, Bubenheim M, Duval-Modeste AB, Joly P, Dominique S, et al. Prospective study to evaluate the association between systemic sclerosis and occupational exposure and review of the literature. Autoimmun Rev (2014) 13(2):151-6. doi:10.1016/j.autrev.2013.10.002

2. Servettaz A, Guilpain P, Goulvestre C, Chereau C, Hercend C, Nicco C, et al. Radical oxygen species production induced by advanced oxidation protein products predicts clinical evolution and response to treatment in systemic sclerosis. Ann Rheum Dis (2007) 66(9):1202-9. doi:10.1136/ard.2006.067504

3. Servettaz A, Goulvestre C, Kavian N, Nicco C, Guilpain P, Chereau C, et al. Selective oxidation of DNA topoisomerase 1 induces systemic sclerosis in the mouse. JImmunol (2009) 182(9):5855-64. doi:10.4049/jimmunol. 0803705

4. Maumus M, Guerit D, Toupet K, Jorgensen C, Noel D. Mesenchymal stem cell-based therapies in regenerative medicine: applications in rheumatology. Stem Cell Res Ther (2011) 2(14):6. doi:10.1186/scrt55

5. Maria AT, Toupet K, Bony C, Pirot N, Vozenin MC, Petit B, et al. Anti-fibrotic, anti-oxidant and immunomodulatory effects of mesenchymal stem cells in HOCl-induced systemic sclerosis. Arthritis Rheumatol (2016) 68(4):1013-25. doi:10.1002/art.39477

6. Vanneaux V, Farge-Bancel D, Lecourt S, Baraut J, Cras A, Jean-Louis F, et al. Expression of transforming growth factor beta receptor II in mesenchymal stem cells from systemic sclerosis patients. BMJ Open (2013) 3(1):e001890. doi:10.1136/bmjopen-2012-001890

7. Cipriani P, Marrelli A, Benedetto PD, Liakouli V, Carubbi F, Ruscitti P, et al. Scleroderma mesenchymal stem cells display a different phenotype from bone marrow) and histocompatibility (autologous, allogenic, and xenogenic) (12). In addition, according to the very first studies in humans, MSC-based therapy was well tolerated and seemed efficient for refractory SSc, including those with severe vascular complications such as of digital ulcers or distal limb necrosis (28). These promising results still need to be confirmed in the ongoing clinical trials and further randomized controlled studies.

\section{AUTHOR CONTRIBUTIONS}

Design of the study: DN, CJ, and PG. Acquisition of data: GF, CB, RG, AM, AQ, and SR. Data analysis: GF, CB, RG, AM, PG, and DN. Manuscript preparation: DN, GF, and PG. All authors reviewed the manuscript and gave final approval for the work.

\section{FUNDING}

Work in the laboratory INSERM U1183 was supported by the INSERM Institute and the University of Montpellier. We are indebted to Association des Sclérodermiques de France (ASF) for funding. AM received a fellowship from French Health ministry and INSERM institute for this work. We acknowledge the Agence Nationale pour la Recherche for support of the national infrastructure: "ECELLFRANCE: Development of a national adult mesenchymal stem cell based therapy platform" (ANR-11-INSB-005).

\section{SUPPLEMENTARY MATERIAL}

The Supplementary Material for this article can be found online at http://journal.frontiersin.org/article/10.3389/fimmu.2017.00988/ full\#supplementary-material.

healthy controls; implications for regenerative medicine. Angiogenesis (2013) 16(3):595-607. doi:10.1007/s10456-013-9338-9

8. Cipriani P, Di Benedetto P, Liakouli V, Del Papa B, Di Padova M, Di Ianni M, et al. Mesenchymal stem cells (MSCs) from scleroderma patients (SSc) preserve their immunomodulatory properties although senescent and normally induce T regulatory cells (Tregs) with a functional phenotype: implications for cellular-based therapy. Clin Exp Immunol (2013) 173(2):195-206. doi:10.1111/cei.12111

9. Capelli C, Zaccara E, Cipriani P, Di Benedetto P, Maglione W, ndracco $\mathrm{R}$, et al. Phenotypical and functional characteristics of 'in vitro' expanded adipose-derived mesenchymal stromal cells from patients with systemic sclerosis. Cell Transplant (2017) 26(5):841-54. doi:10.3727/096368 917X694822

10. Maria AT, Maumus M, Le Quellec A, Jorgensen C, Noel D, Guilpain P. Adipose-derived mesenchymal stem cells in autoimmune disorders: state of the art and perspectives for systemic sclerosis. Clin Rev Allergy Immunol (2017) 52(2):234-59. doi:10.1007/s12016-016-8552-9

11. Djouad F, Bony C, Haupl T, Uze G, Lahlou N, Louis-Plence P, et al. Transcriptional profiles discriminate bone marrow-derived and synovium-derived mesenchymal stem cells. Arthritis Res Ther (2005) 7(6):R1304-15. doi:10.1186/ar1594

12. Maria AT, Toupet K, Maumus M, Fonteneau G, Le Quellec A, Jorgensen C, et al. Human adipose mesenchymal stem cells as potent anti-fibrosis therapy for systemic sclerosis. J Autoimmun (2016) 70:31-9. doi:10.1016/j.jaut.2016.03.013

13. Griffin M, Ryan CM, Pathan O, Abraham D, Denton CP, Butler PE. Characteristics of human adipose derived stem cells in scleroderma in 
comparison to sex and age matched normal controls: implications for regenerative medicine. Stem Cell Res Ther (2017) 8(1):23. doi:10.1186/s13287016-0444-7

14. Choo KB, Tai L, Hymavathee KS, Wong CY, Nguyen PN, Huang CJ, et al. Oxidative stress-induced premature senescence in Wharton's jelly-derived mesenchymal stem cells. Int J Med Sci (2014) 11(11):1201-7. doi:10.7150/ ijms. 8356

15. Ko E, Lee KY, Hwang DS. Human umbilical cord blood-derived mesenchymal stem cells undergo cellular senescence in response to oxidative stress. Stem Cells Dev (2012) 21(11):1877-86. doi:10.1089/scd.2011.0284

16. Ankrum JA, Ong JF, Karp JM. Mesenchymal stem cells: immune evasive, not immune privileged. Nat Biotechnol (2014) 32(3):252-60. doi:10.1038/nbt.2816

17. Cipriani P, Di Benedetto P, Ruscitti P, Campese AF, Liakouli V, Carubbi F, et al. Impaired endothelium-mesenchymal stem cells cross-talk in systemic sclerosis: a link between vascular and fibrotic features. Arthritis Res Ther (2014) 16(5):442. doi:10.1186/s13075-014-0442-Z

18. Orciani M, Svegliati S, Gorbi S, Spadoni T, Lazzarini R, Regoli F, et al. Alterations of ROS pathways in scleroderma begin at stem cell level. J Biol Regul Homeost Agents (2013) 27(1):211-24.

19. Liang X, Ding Y, Zhang Y, Tse HF, Lian Q. Paracrine mechanisms of mesenchymal stem cell-based therapy: current status and perspectives. Cell Transplant (2014) 23(9):1045-59. doi:10.3727/096368913X667709

20. Hwang ES. Senescence suppressors: their practical importance in replicative lifespan extension in stem cells. Cell Mol Life Sci (2014) 71(21):4207-19. doi:10.1007/s00018-014-1685-1

21. Byon CH, Javed A, Dai Q, Kappes JC, Clemens TL, Darley-Usmar VM, et al. Oxidative stress induces vascular calcification through modulation of the osteogenic transcription factor Runx2 by AKT signaling. J Biol Chem (2008) 283(22):15319-27. doi:10.1074/jbc.M800021200

22. Higuchi M, Dusting GJ, Peshavariya H, Jiang F, Hsiao ST, Chan EC, et al. Differentiation of human adipose-derived stem cells into fat involves reactive oxygen species and Forkhead box O1 mediated upregulation of antioxidant enzymes. Stem Cells Dev (2013) 22(6):878-88. doi:10.1089/scd. 2012.0306

23. Denu RA, Hematti P. Effects of oxidative stress on mesenchymal stem cell biology. Oxid Med Cell Longev (2016) 2016:2989076. doi:10.1155/2016/2989076
24. Larghero J, Farge D, Braccini A, Lecourt S, Scherberich A, Fois E, et al. Phenotypical and functional characteristics of in vitro expanded bone marrow mesenchymal stem cells from patients with systemic sclerosis. Ann Rheum Dis (2008) 67(4):443-9. doi:10.1136/ard.2007.071233

25. Scuderi N, Ceccarelli S, Onesti MG, Fioramonti P, Guidi C, Romano F, et al. Human adipose-derived stromal cells for cell-based therapies in the treatment of systemic sclerosis. Cell Transplant (2013) 22(5):779-95. doi:10.3727/09636 8912X639017

26. Bocelli-Tyndall C, Bracci L, Spagnoli G, Braccini A, Bouchenaki M, Ceredig R, et al. Bone marrow mesenchymal stromal cells (BM-MSCs) from healthy donors and auto-immune disease patients reduce the proliferation of autologous- and allogeneic-stimulated lymphocytes in vitro. Rheumatology (Oxford) (2007) 46(3):403-8. doi:10.1093/rheumatology/ kel267

27. Kizilay Mancini O, Shum-Tim D, Stochaj U, Correa JA, Colmegna I. Age, atherosclerosis and type 2 diabetes reduce human mesenchymal stromal cell-mediated T-cell suppression. Stem Cell Res Ther (2015) 6:140. doi:10.1186/ s13287-015-0127-9

28. Christopeit M, Schendel M, Foll J, Muller LP, Keysser G, Behre G. Marked improvement of severe progressive systemic sclerosis after transplantation of mesenchymal stem cells from an allogeneic haploidentical-related donor mediated by ligation of CD137L. Leukemia (2008) 22(5):1062-4. doi:10.1038/ sj.leu. 2404996

Conflict of Interest Statement: The authors declare that the research was conducted in the absence of any commercial or financial relationships that could be construed as a potential conflict of interest.

Copyright (c) 2017 Fonteneau, Bony, Goulabchand, Maria, Le Quellec, Rivière, Jorgensen, Guilpain and Noël. This is an open-access article distributed under the terms of the Creative Commons Attribution License (CC BY). The use, distribution or reproduction in other forums is permitted, provided the original author(s) or licensor are credited and that the original publication in this journal is cited, in accordance with accepted academic practice. No use, distribution or reproduction is permitted which does not comply with these terms. 